\title{
The relationship between blood lipids and plasma amyloid beta is depend on blood pressure: a population-based cross- sectional study
}

Ningwei Hu ${ }^{1 \dagger}$, Ling Gao ${ }^{1 \dagger}$, Yu Jiang ${ }^{1}$, Shan Wei ${ }^{1}$, Suhang Shang ${ }^{1}$, Chen Chen ${ }^{1}$, Liangjun Dang ${ }^{1}$, Jin Wang ${ }^{1}$, Kang Huo ${ }^{1}$, Meiying Deng ${ }^{1}$, Jingyi Wang ${ }^{2}$ and Qiumin $\mathrm{Qu}^{1 *}$

\begin{abstract}
Background: It is believed that deposition of amyloid beta $(A \beta)$ in the brain is the central pathological changes of Alzheimer's disease (AD), which triggers a series of pathological processes. However, the relationship between dyslipidemia and $A D$ is uncertain. Considering the peripheral $A \beta$ levels are related to brain $A \beta$ deposition, we explore the relationships between blood lipids and plasma $A \beta$.

Methods: Participants who lived in the selected village of Xi'an for more than 3 years were enrolled, aged 40-85 years ( $n=1282,37.9 \%$ male). Fasting blood lipid, plasma $A \beta$ levels, basic information and living habits were measured. Multiple linear regressions were used.

Results: In total population, blood lipids were not associated with plasma A $\beta$. After stratified by blood pressure, serum total cholesterol (TC) and low-density lipoprotein (LDL-C) were positively associated with plasma $A \beta_{42}$ levels $\left(\beta_{\mathrm{TC}}=0.666, P_{\mathrm{TC}}=0.024 ; \beta_{\mathrm{LDL}-\mathrm{c}}=0.743, P_{\mathrm{LDL}-\mathrm{c}}=0.011\right.$, respectively $)$ in normal blood pressure. $\mathrm{LDL}-\mathrm{c}$ was negatively associated with plasma $A \beta_{40}$ levels $(\beta=-0.986, P=0.037$ ) in high blood pressure.
\end{abstract}

Conclusion: Elevated plasma $A \beta_{42}$ levels are associated with higher TC and LDL-C in normal blood pressure. Elevated plasma $A \beta_{40}$ levels are associated with lower LDL-C in high blood pressure. This indicated that the relationships between blood lipids and plasma $A \beta$ were confounded by blood pressure.

Keywords: Alzheimer's disease, Amyloid beta, Blood lipids, Blood pressure

\section{Introduction}

Alzheimer's disease (AD) is the most common cause of dementia. Toxic plaque formed by the deposition of amyloid beta $(A \beta)$ peptide in the brain is the main characteristic pathogenesis of $\mathrm{AD}[1]$. $\mathrm{A} \beta$ peptides are natural products of metabolism consisting of 39 to 43 amino acids, formed by fragmentation of amyloid- $\beta$ protein precursor (APP) through the sequential enzymatic actions of secretases [2]. In the process of $A \beta$ formation, APP is first cleaved by $\beta$-secretase (known as BACE1), releasing

\footnotetext{
* Correspondence: quqiumin@126.com

${ }^{\dagger}$ Ningwei Hu and Ling Gao contributed equally to this work.

${ }^{1}$ Department of Neurology, The First Affiliated Hospital of Xi'an Jiaotong

University, 277 West Yanta Rd, Xi'an 710061, China

Full list of author information is available at the end of the article
}

SAPP $\beta$ into the extra cellular fluid and cerebrospinal fluid (CSF). The remaining fragment is then cleaved by $\gamma$ secretase to produce damaging amyloid- $\beta 42\left(A \beta_{42}\right)$ and other $A \beta$ isoform $\left(A \beta_{40}\right.$ down to $\left.A \beta_{17}\right)$. In addition, fulllength APP is also cleaved by $\beta$ and $\alpha$-secreatase to form $A \beta_{16}$ down to $A \beta_{13}$ [3]. Under normal circumstance, most of the production is amyloid- $\beta 40\left(A \beta_{40}\right)$ and only a small amount of $A \beta_{42}$ which is more likely to deposit and has neurotoxic. $A \beta$ present in the brain can be eliminated by various means, including degradation of $A \beta$ degrading enzymes, cell clearance, blood brain barrier (BBB) transport, CSF and interstitial lymphatic drainage, clearance of peripheral cells and tissues, etc. Due to the imbalance of $A \beta$ production and clearance, a large number of neuritic plaques (formed by $\mathrm{A} \beta$ deposition) are present in the cerebral

(C) The Author(s). 2020 Open Access This article is distributed under the terms of the Creative Commons Attribution 4.0 International License (http://creativecommons.org/licenses/by/4.0/), which permits unrestricted use, distribution, and 
cortex, hippocampus, and some subcortical nuclei. $A \beta$ deposition in the brain may be the initiating factor in $A D$ process, which is called "amyloid hypothesis" [4]. It has been suggested that $A \beta$ levels in the brain and plasma are in a dynamic balance. Deposition of $A \beta$ in the brain subsequently affects plasma concentration [5]. Peripheral transport of $A \beta$ can reduce its accumulation in the brain, suggesting that the $A \beta$ concentration in plasma is related to the deposition of $A \beta$ in the brain [6].

Dyslipidemia is one of the important risk factor for cardiovascular disease and stroke. Numerous studies showed that blood lipids were also significantly associated with the risk of AD [7-9], but with conflicting results. Several epidemiological, laboratory research and clinical studies supported the hypothesis that higher levels of cholesterol may induce the development of AD [10-13], while others had not confirmed or inversed association with the risk of $\mathrm{AD}$ [14-16]. The effects of blood lipids levels on $A \beta$ deposition in the brain were unclear.

Considering that plasma $A \beta$ concentration is related to cerebral $A \beta$ levels and mounting evidence had indicated that blood pressure is related to plasma $A \beta$ levels significantly, we conducted a cross-sectional study to explore the effects of blood pressure on the relationships between blood lipids and plasma $A \beta$ levels in a community population.

\section{Methods}

\section{Participants}

From October 2014 to March 2015, all aged 40 or more villagers in Qubao village which taken by cluster sampling method near Xi'an were enrolled. There were similar lifestyles and population composition between this village and other rural areas of Xi'an. Inclusion criteria: 1) resident villager or who has lived in this area for 3 years or more, 2) agree to participate in this study and provided informed consent $(N=2011)$. Exclusion criteria: 1$)$ severe cardiac, pulmonary, liver, kidney dysfunction, hematological, acute infection, or tumors, 2) those who have taken lipidlowering drugs $(n=70), 3)$ those who showed aberrant plasma $A \beta_{42}, A \beta_{40}$ levels $(n=529)$ or blood lipids levels $(n=2)$ (exceeding 3 standard deviations from the mean), 4) sample hematolysis $(n=128)$. Total of 1282 participants were included in our analysis (Fig. 1).

\section{Definition of covariates}

The diseases and related conditions involved in this study are defined according to the guidelines $[17,18]$ as follows: 1) A person with a current systolic blood pressure (SBP) $\geq 140 \mathrm{mmHg}$ and/or diastolic blood pressure (DBP) $\geq 90$ $\mathrm{mmHg}$ is defined as high blood pressure. On the contrary, it is defined as normal blood pressure. Blood pressure measured with taking antihypertensive drugs and/or a current SBP $\geq 140 \mathrm{mmHg}$ and/or a DBP $\geq 90 \mathrm{mmHg}$ is defined as a hypertensive patient. 2) High fasting blood glucose (FBG) was defined as at least $7 \mathrm{mmol} / \mathrm{L}$. 3) According the guidelines for the prevention and treatment of dyslipidemia in Chinese adults (revised edition 2016), high serum total cholesterol (TC) was defined as at least 5.18 $\mathrm{mmol} / \mathrm{L}$, high triglyceride (TG) was defined as at least $1.70 \mathrm{mmol} / \mathrm{L}$, high serum low-density lipoprotein (LDL-c) was defined as at least $3.37 \mathrm{mmol} / \mathrm{L}$ and low serum highdensity lipoprotein (HDL-c) was defined as less than 1.04 $\mathrm{mmol} / \mathrm{L}$. Any abnormality in blood lipids is defined as dyslipidemia. 4) Apolipoprotein E (ApoE ع4) carriers were defined as having at least one allele of $\varepsilon 4$, while noncarriers referred to the ones without any $\varepsilon 4$ allele.

\section{Questionnaire survey}

A uniform questionnaire was used for all subjects, first of all, face to face consultation to collect general information, followed by physical examination and blood sample collection.

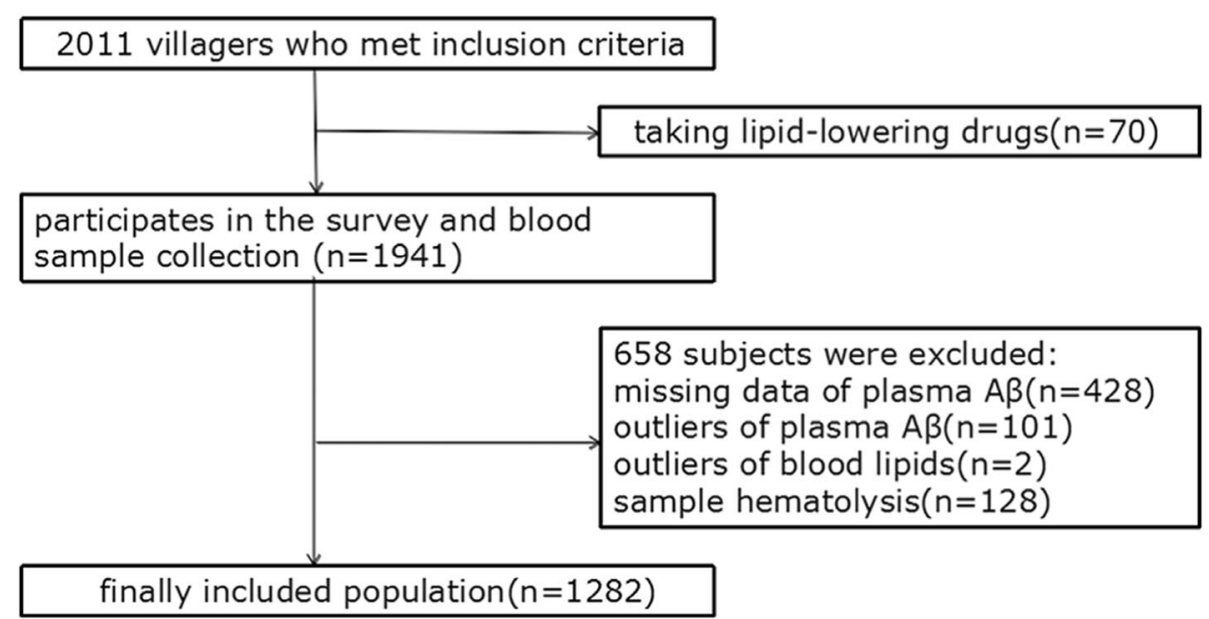

Fig. 1 Flow chart of participant screening. $A \beta$, amyloid beta 


\section{Blood pressure measurement}

Blood pressure (BP) was measured by a nurse using a mercury sphygmomanometer on each participant's right arm with a regular adult cuff (Shanghai Medical Instruments Co. Shanghai, China) in the morning, before breakfast (from 8 a.m. to 10 a.m.). Setting BP was measure again after $10 \mathrm{~min}$ of rest, and the average of the twice was recorded.

\section{Laboratory evaluation}

All subjects were collected $5 \mathrm{ml}$ of venous blood sample from $8 \mathrm{a} . \mathrm{m}$. in the morning (at least $8 \mathrm{~h}$ on an empty stomach). 1) Then the blood sample was placed in a serum tube containing a coagulant and was gently inverted upside and down and stood for $30 \mathrm{~min}$. Next, the sample was centrifuged at $3000 \mathrm{rpm}$ for $15 \mathrm{~min}$ at room temperature for $2 \mathrm{~h}$ and quickly stored at $-80^{\circ} \mathrm{C}$ until later measurement. TC, TG, HDL-c and LDL-c levels were detected by enzymatic method using an automated biochemical analyzer (C501, Roche, Sweden). Quality indicators accord with the quality requirements set by the US National Cholesterol Education Program. 2) Plasma levels of $A \beta_{40}, A \beta_{42}$ were measured with commercially available quantitative enzyme-linked immunosorbent assay kits (ELISA, Yuanye Co. Shanghai, China), and the sensitivity of each assay was $1.0 \mathrm{pg} / \mathrm{ml}$, respectively. Measurements were performed using an RT6000 analyzer (Rayto Co. Shenzhen. China) at $450 \mathrm{~nm}$, and concentrations were calculated from the standard curve. All measurements were performed in duplicate and the results averaged. The intra-assay and inter-assay coefficients of variation were less than 7 and 9\%, respectively. 3) Determination of ApoE genotypes: According to manufacturer's protocol, genomic DNA from blood samples in the EDTA anticoagulant tubes was extracted by blood genomic deoxyribonucleic acid (DNA) extraction kit (Tiangen Co. Beijing. China). We amplified 244 base pair of the ApoE gene fragment using a polymerase chain reaction (PCR) thermocycler, the length of which included two polymorphic sites at amino acid residues 112 and 158(15). Sequence of the PCR products was tested by Sanger

Table 1 Characteristics of the total study population

\begin{tabular}{|c|c|c|c|c|c|c|}
\hline Characteristics & Total $(n=1282)$ & Dyslipidemia $(n=644)$ & Normal blood lipids $(n=638)$ & t or $U$ or Chi square & df & $P$ value \\
\hline Age, years & $55.70(10.19)$ & $56.74(10.1)$ & 54.66(10.19) & -3.673 & 1280 & $<0.001$ \\
\hline Male, n(\%) & $486(37.9)$ & 242(37.6) & $244(38.2)$ & 0.061 & 1 & 0.806 \\
\hline Education, years & $7(4,8)$ & $7(3,8)$ & $7(5,9)$ & $190,461.5$ & - & 0.023 \\
\hline Hypertension, n(\%) & $601(46.9)$ & $356(55.3)$ & 245(38.4) & 36.663 & 1 & $<0.001$ \\
\hline Diabetes mellitus, n(\%) & $146(11.4)$ & $91(14.1)$ & $55(8.6)$ & 9.641 & 1 & 0.002 \\
\hline Cardiovascular disease, $\mathrm{n}(\%)$ & $73(5.7)$ & $40(6.2)$ & $33(5.2)$ & 0.644 & 1 & 0.422 \\
\hline Transient ischemic attack, n(\%) & $23(1.8)$ & $13(2.0)$ & $10(1.6)$ & 0.370 & 1 & 0.543 \\
\hline Stroke, $n(\%)$ & $72(5.6)$ & $41(6.4)$ & $31(4.9)$ & 1.374 & 1 & 0.241 \\
\hline Smoking, $n(\%)$ & $349(27.2)$ & $170(26.4)$ & 179(28.1) & 0.445 & 1 & 0.505 \\
\hline Drinking, n(\%) & $168(13.1)$ & $93(14.4)$ & $76(11.8)$ & 2.030 & 1 & 0.154 \\
\hline Lack of physical activity, n(\%) & $225(17.6)$ & 123(19.1) & 102(16.0) & 2.145 & 1 & 0.143 \\
\hline Pulse rate, bpm & $75.48(8.74)$ & $75.51(8.58)$ & $75.44(8.90)$ & -0.151 & 1280 & 0.880 \\
\hline Waistline, cm & $84.76(8.96)$ & $86.82(8.99)$ & $82.68(8.44)$ & -8.482 & 1280 & $<0.001$ \\
\hline Hip circumference, $\mathrm{cm}$ & $96.39(6.56)$ & $97.48(6.76)$ & $95.28(6.17)$ & -6.091 & 1280 & $<0.001$ \\
\hline $\mathrm{BMI}, \mathrm{kg} / \mathrm{m}^{2}$ & $25.13(3.20)$ & $25.69(3.32)$ & $24.57(2.98)$ & -6.346 & 1297.91 & $<0.001$ \\
\hline $\mathrm{SBP}, \mathrm{mmHg}$ & 132.16(19.08) & 135.62(19.58) & $128.67(17.92)$ & -6.637 & 1272.03 & $<0.001$ \\
\hline $\mathrm{DBP}, \mathrm{mmHg}$ & $81.82(10.44)$ & $83.63(10.83)$ & $80.00(9.72)$ & -6.315 & 1267.75 & $<0.001$ \\
\hline $\mathrm{FBG}, \mathrm{mmol} / \mathrm{L}$ & $5.39(5.06,5.77)$ & $5.42(5.07,5.91)$ & $5.35(5.06,5.69)$ & 188,237 & - & 0.009 \\
\hline $\mathrm{TG}, \mathrm{mmol} / \mathrm{L}$ & $1.43(1.03,1.99)$ & $1.99(1.48,2.47)$ & $1.10(0.88,1.39)$ & 53,420 & - & $<0.001$ \\
\hline $\mathrm{TC}, \mathrm{mmol} / \mathrm{L}$ & $5.04(1.01)$ & $5.57(1.02)$ & $4.51(0.64)$ & -22.296 & 1086.03 & $<0.001$ \\
\hline $\mathrm{LDL}-\mathrm{c}, \mathrm{mmol} / \mathrm{L}$ & $3.31(0.89)$ & $3.78(0.89)$ & $2.839(0.56)$ & -22.888 & 1085.95 & $<0.001$ \\
\hline $\mathrm{HDL}-\mathrm{c}, \mathrm{mmol} / \mathrm{L}$ & $1.41(0.31)$ & $1.37(0.32)$ & $1.46(0.30)$ & 5.168 & 1280 & $<0.001$ \\
\hline ApoE $\varepsilon 4, n(\%)$ & $173(13.5)$ & $92(14.3)$ & $81(12.7)$ & 0.180 & 2 & 0.667 \\
\hline
\end{tabular}

Unpaired Student's $t$-test and mean \pm SD were used to compare the difference of the approximately normally distributed continuous variables between dyslipidemia and normal blood lipids. Mann-Whitney $\mathrm{U}$ test and mediam (quartile) were used for the skew distributional data and Chi square and percentage were used for categorical variables. Data are mean (SD), median (interquartile range), or number (percentage). BMI, body mass index. SBP, systolic blood pressure. DBP, diastolic blood pressure. FBG, fast blood glucose. TC, total cholesterol. TG, triglyceride. HDL-c, high-density lipoprotein. LDL-c, low-density lipoprotein. ApoE, apolipoprotein $\mathrm{E}$ 
Table 2 Comparison of plasma A $\beta$ in Dyslipidemia group and Normal blood lipids in total study population $(n=1282)$

\begin{tabular}{|c|c|c|c|c|c|c|c|c|}
\hline & $\mathrm{A} \beta_{42}(\mathrm{pg} / \mathrm{ml})$ & & & & $\mathrm{A} \beta_{40}(\mathrm{pg} / \mathrm{ml})$ & & & \\
\hline & mean (SD) & $t$ & $\mathrm{df}$ & $P$ & mean (SD) & $\mathrm{t}$ & $\mathrm{df}$ & $P$ \\
\hline Dyslipidemia $(n=644)$ & $40.97(6.11)$ & -0.889 & 1269.67 & 0.374 & $52.31(8.79)$ & 0.865 & 1280 & 0.387 \\
\hline Normal blood lipids $(n=638)$ & $40.65(6.62)$ & & & & $52.74(9.04)$ & & & \\
\hline High TC $(n=515)$ & $41.11(6.16)$ & -1.389 & 1142.34 & 0.165 & $52.20(8.96)$ & 1.077 & 1280 & 0.282 \\
\hline Normal TC $(n=767)$ & $40.61(6.50)$ & & & & $52.74(8.89)$ & & & \\
\hline High TG $(n=447)$ & $40.98(6.03)$ & -0.715 & 1280 & 0.475 & $52.65(8.91)$ & -0.371 & 1280 & 0.710 \\
\hline Normal TG $(n=835)$ & $40.72(6.54)$ & & & & $52.46(8.92)$ & & & \\
\hline High LDL-C $(n=544)$ & $41.10(6.03)$ & -1.398 & 122,239 & 0.162 & $52.09(8.96)$ & 1.485 & 1280 & 0.138 \\
\hline Normal LDL-c $(n=738)$ & $40.60(6.60)$ & & & & $52.84(8.88)$ & & & \\
\hline Low HDL-c $(n=116)$ & $40.89(6.48)$ & -0.142 & 1280 & 0.887 & $53.18(9.34)$ & -0.825 & 1280 & 0.409 \\
\hline Normal HDL-c $(n=1166)$ & $40.80(6.36)$ & & & & $52.46(8.87)$ & & & \\
\hline
\end{tabular}

Unpaired Student's $t$-test were used to compare the difference of plasma $A \beta_{42}, A \beta_{40}$ between the groups of the covariates. Data are shown as mean (SD). $A \beta$, amyloid beta. TC, total cholesterol. TG, triglyceride. HDL-c, high-density lipoprotein. LDL-c, low-density lipoprotein
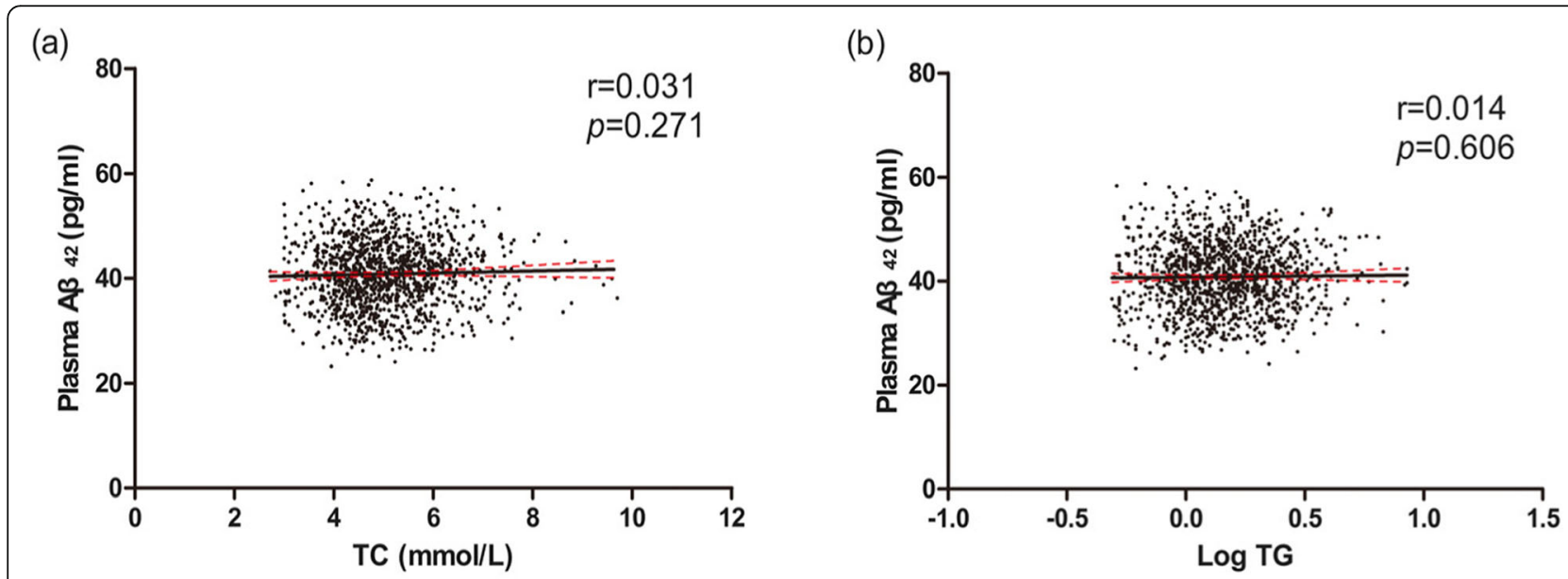

(c)

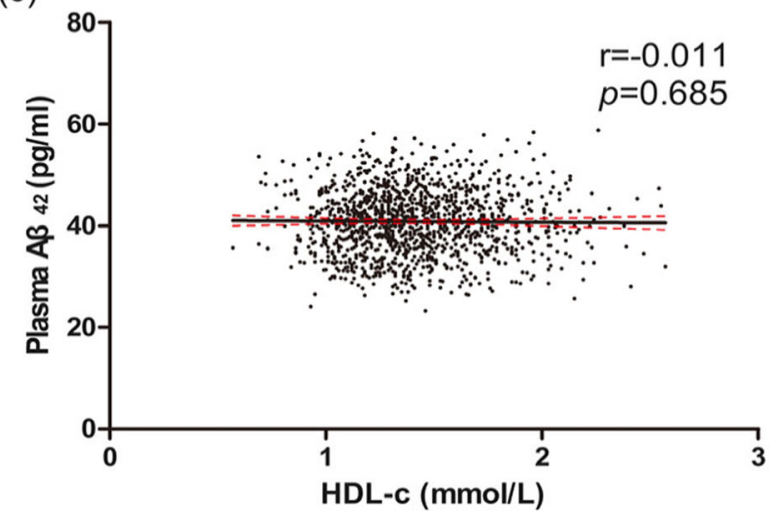

(d)

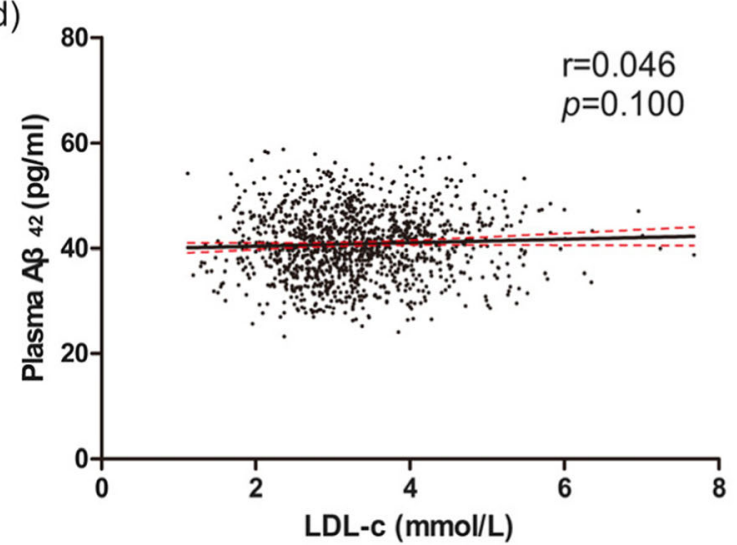

Fig. 2 Correlations of TC, Log TG, HDL-C, LDL-C and plasma $A \beta_{42}$ in total study population. Simple linear correlations between $T C$, $L O g$ TG, HDL-C, $\mathrm{LDL}-\mathrm{c}$ and plasma $A \beta_{42}$ were shown respectively in picture $(\mathbf{a}, \mathbf{b}, \mathbf{c}, \mathbf{d}) . A \beta$, amyloid beta. TC, total cholesterol. TG, triglyceride. $H D L-c$, high-density lipoprotein. LDL-c, low-density lipoprotein 
sequencing (Sangon Co. Shanghai. China). Finally, we used direct interpretation of the sequencing chromatogram to determine the ApoE genotype.

\section{Statistical analysis}

Before doing statistical analysis, we tested the distribution of each covariate by using Skewness, Kurtosis and P-P plots. Covariates that nearly conformed to normal distribution included age, pulse rate, waistline, hip circumference, BMI, SBP, DBP, TC, HDL-c, LDL-c which were expressed as mean (SD) and were compared between different groups by using an unpaired Student's $t$ test. Non-normal distribution covariates included education, levels of TG and FBG were expressed as median (interquartile range) and were compared by MannWhitney U-test. Categorical variables were expressed as the number (percentage) and were compared by $X^{2}$ test. For serum lipid, participants were divided into dyslipidemia group and normal blood lipids group. Differences between two groups were compared. We used simple linear correlation scatter plot to roughly observe the linear trend between blood lipids and plasma $A \beta$ levels. We performed multiple liner regression models to explore the statistical significance of the association after adjusting for other confounding factors including age, sex, education years, smoking, drinking, physical activity level, and history of heart disease, waist circumference, hip circumference, BMI, pulse rate, SBP, DBP, FBG and ApoE $\varepsilon 4$ genotype (ApoE is involved in the regulation of A $\beta$ metabolism, aggregation and deposition [19]).

Two secondary analyses were performed. First, associations between blood lipids and $\mathrm{A} \beta$ were analyzed in total study population. Because $\mathrm{TC}$ was collinear with LDL-c, two models were built. Model 1: TG, TC, HDL-c and other covariates mentioned above. Model 2: TG, LDL-c, HDL-c and other covariates mentioned above. Second, to rule out the possibility of BP affecting the relationship between blood lipids and plasma $A \beta$, we divided the total population into high blood pressure and normal blood pressure
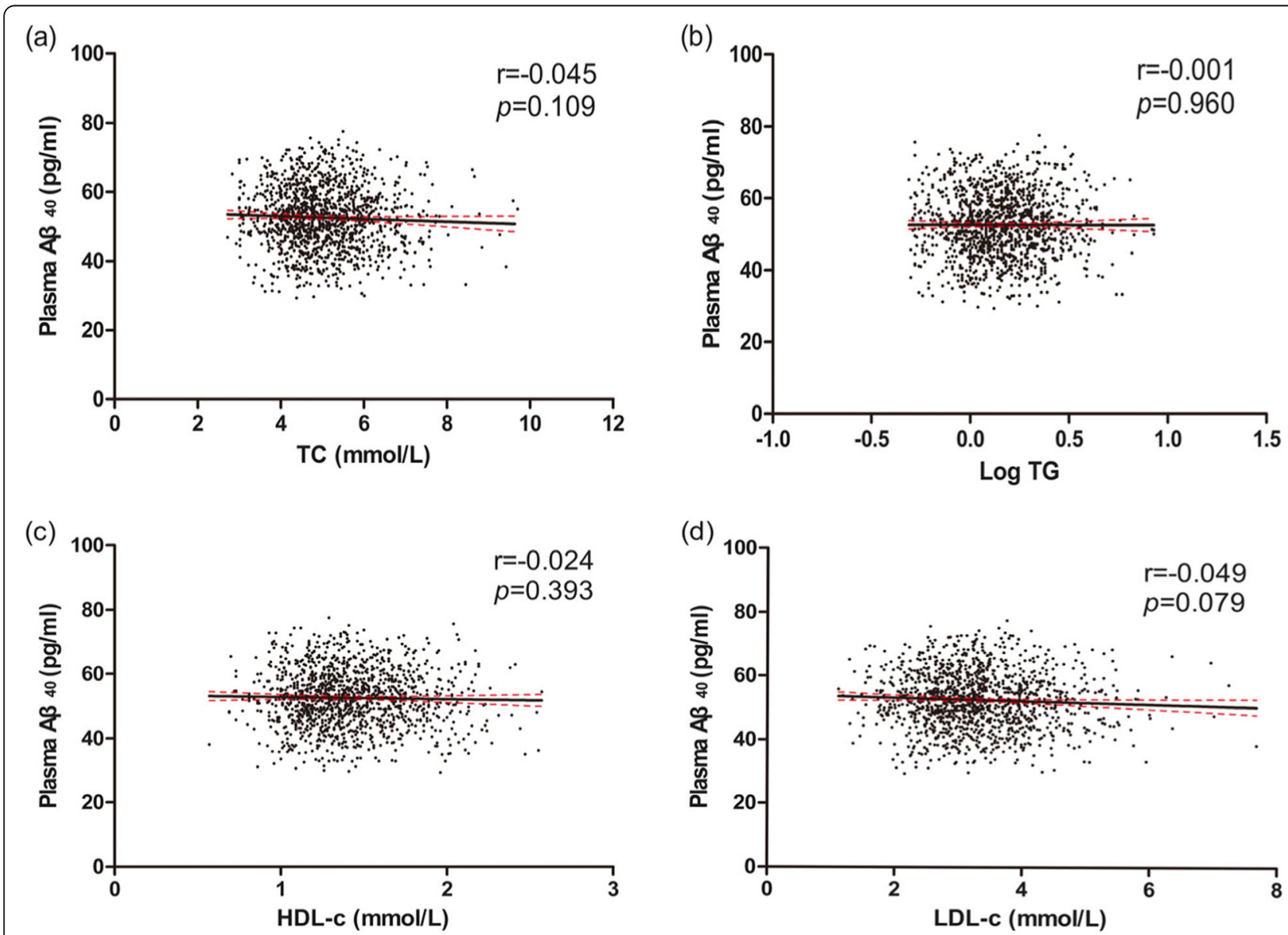

Fig. 3 Correlations of TC, Log TG, HDL-C, LDL-C and plasma $A \beta_{40}$ in total study population. Simple linear correlations between TC, Log TG, HDL-C, $\mathrm{LDL}-\mathrm{c}$ and plasma $A \beta_{40}$ were shown respectively in picture $(\mathbf{a}, \mathbf{b}, \mathbf{c}, \mathbf{d}) . A \beta$, amyloid beta. TC, total cholesterol. TG, triglyceride. $\mathrm{HDL}-\mathrm{c}$, high-density lipoprotein. LDL-c, low-density lipoprotein 
according to the standard of SBP greater than or equal to $140 \mathrm{mmHg}$ and/or DBP greater than or equal to $90 \mathrm{mmHg}$ and compared the relationship again in new two-tiered crowd (Model 3, Model 4).

All statistical analyses were performed with IBM SPSS Statistics version 24.0. A two-side $P$ value of less than 0.05 was the threshold for statistical significance.

\section{Results}

\section{Characteristics of the population}

As shown in the Table 1, participants with dyslipidemia ( $n=644$ ) were older, higher ratios of hypertension, diabetes mellitus, higher levels of BMI, SBP, DBP, FBG, TC, LDL-c, TG and lower levels of education and HDL-c than those with normal lipids.

\section{Association between plasma $A \beta$ levels and blood lipids in the total population}

In the total population, plasma $A \beta$ levels had no differences between dyslipidemia group and normal lipids group (Table 2). No linear trends were found (Figs. 2, 3). After adjusting for confounding factors as described above, no correlations were found between blood lipids and plasma $\mathrm{A} \beta$ levels (Table 3).

Table 3 Multiple linear regression of blood lipids and plasma A $\beta$ levels in total study participants $(n=1282)$

\begin{tabular}{|c|c|c|c|c|c|c|}
\hline & \multicolumn{3}{|c|}{$A \beta_{42}(\mathrm{pg} / \mathrm{ml})$} & \multicolumn{3}{|c|}{$\mathrm{A} \beta_{40}(\mathrm{pg} / \mathrm{ml})$} \\
\hline & $\beta$ & $\mathrm{t}$ & $P$ value & $\beta$ & $\mathrm{t}$ & $P$ value \\
\hline \multicolumn{7}{|l|}{ Model 1} \\
\hline TG & -0.030 & -0.122 & 0.903 & 0.087 & 0.256 & 0.798 \\
\hline TC & 0.254 & 1.156 & 0.248 & -0.356 & -1.156 & 0.248 \\
\hline $\mathrm{HDL}-\mathrm{C}$ & -0.448 & -0.615 & 0.539 & -0.625 & -0.611 & 0.541 \\
\hline ApoE $\varepsilon 4$ & 0.955 & 1.813 & 0.070 & 0.278 & 0.376 & 0.707 \\
\hline \multicolumn{7}{|l|}{ Model 2} \\
\hline TG & -0.001 & -0.004 & 0.997 & 0.042 & 0.134 & 0.893 \\
\hline LDL-C & 0.325 & 1.483 & 0.138 & -0.442 & -1.439 & 0.150 \\
\hline $\mathrm{HDL}-\mathrm{C}$ & -0.252 & -0.385 & 0.700 & -0.908 & -0.988 & 0.323 \\
\hline ApoE ع4 & 0.946 & 1.797 & 0.073 & 0.288 & 0.390 & 0.697 \\
\hline
\end{tabular}

$\beta$, the unstandardized regression coefficient

Model 1: adjust for sex, age, education years, smoking, drinking, lack of physical activity, cardiovascular disease, waistline and lip circumference, pulse rate, SBP, DBP, FBG, TC, TG, HDL-C, BMI and ApoE genotype. BMI, body mass index. SBP, systolic blood pressure. DBP, diastolic blood pressure. FBG, fast blood glucose $A \beta$, amyloid beta. TC, total cholesterol. TG, triglyceride. HDL-C, high-density lipoprotein. LDL-c, low-density lipoprotein. ApoE, apolipoprotein $E$ Model 2: adjust for sex, age, education years, smoking, drinking, lack of physical activity, cardiovascular disease, waist and lip circumference, pulse rate, SBP, DBP, FBG, LDL-C, TG, HDL-C, BMI and ApoE genotype. BMI, body mass index. SBP, systolic blood pressure. DBP, diastolic blood pressure. FBG, fast blood glucose $A \beta$, amyloid beta. TC, total cholesterol. TG, triglyceride. $\mathrm{HDL}-\mathrm{c}$, high-density lipoprotein. LDL-c, low-density lipoprotein. ApoE, apolipoprotein E

\section{The effects of blood pressure on plasma $A \beta$ levels and blood lipids levels}

After re-stratified by blood pressure (Table 4), participants with high blood pressure $(n=548)$ were older, more diabetes mellitus, cardiovascular disease and stroke, high levels of waistline, hip circumference, BMI, SBP, DBP, FBG, TC, LDL-c, TG and a lower levels of education and HDL-c levels.

\section{Association of plasma $A \beta$ levels and blood lipids stratified by blood pressure}

In normal blood pressure group, $A \beta_{42}$ levels were higher in the high TC and high LDL-c group than that in the normal group (Table 5). Positive linear trends were found between TC, LDL-c levels and plasma $A \beta_{42}$ levels in normal blood pressure group (Fig. 4a, b). Negative linear trend was found between LDL-c levels and plasma $\mathrm{A} \beta_{40}$ levels in high blood pressure group $(\mathrm{r}=-0.089$, $P=0.038$ ). Consistent with previous analysis, TC and LDL-c were independently and positively associated with plasma $A \beta_{42}$ levels after re-stratified in the normal blood pressure. LDL-c was negatively associated with plasma $\mathrm{A} \beta_{40}$ levels in high blood pressure group (Table 6).

\section{Discussion}

In this population-based study, we found that $\mathrm{TC}$ and LDL-c were positively correlated with plasma $A \beta_{42}$ levels in normal blood pressure. LDL-c was negatively associated with plasma $A \beta_{40}$ levels in the high blood pressure. This finding was independent of age, sex, ApoE $\varepsilon 4$ and other confounding factors. This indicated that the relationships between blood lipids and plasma $A \beta$ were confounded by blood pressure.

Studies have shown that hyperlipidemia may play a role in the development of AD [20]. A 13-year follow-up study showed that higher LDL-c and TC levels were associated with an increased risk of AD [7]. A study containing 7053 community-dwelling elderly suggested low TG was associated with decreased incident $\mathrm{AD}$ in women [21]. Elevated HDL-c levels might be associated with a decreased risk of $\mathrm{AD}$ were also found in elderly individuals [8]. Therefore, elevated blood lipids may play a role in the progression of $\mathrm{AD}$ [9].

However, the relationship between blood lipids and plasma $A \beta$ is not fully determined. Positively correlation of HDL-c levels with $A \beta_{42}$ in not using statins was observed and no relationships of $A \beta_{42}$ with TC and LDL-C [22]. Inverse trend was observed between HDL-c and $\mathrm{A} \beta_{42}$ levels, although not significant [23]. Regression analysis considering the multiple influences of baseline parameters TC, LDL-c, HDL-c, TG, BMI, lnHbA1c and presence of at least one ApoE $\varepsilon 4$ allele on the $\ln A \beta_{42}$ at 5 years revealed TC as the only significant predictor. Excluding TC from the list of independent variables, LDL- 
Table 4 Comparisons of High blood pressure group and Normal blood pressure group

\begin{tabular}{|c|c|c|c|c|c|}
\hline Characteristics & High blood pressure group $(n=548)$ & Normal blood pressure group $(n=734)$ & t or $U$ or Chi square & $d f$ & $P$ value \\
\hline Age, years & $59.03(9.88)$ & $53.21(9.70)$ & -10.536 & 1280 & $<0.001$ \\
\hline Male, n(\%) & $210(38.3)$ & 276(37.6) & 0.069 & 1 & 0.793 \\
\hline Education, years & $6(3,8)$ & $8(5,9)$ & 171,805 & - & $<0.001$ \\
\hline Diabetes mellitus, n(\%) & $88(16.1)$ & $58(7.9)$ & 20.684 & 1 & $<0.001$ \\
\hline Cardiovascular disease, $\mathrm{n}(\%)$ & $40(7.3)$ & $33(4.5)$ & 4.592 & 1 & 0.032 \\
\hline Transient ischemic attack, n(\%) & $12(2.2)$ & $11(1.5)$ & 0.851 & 1 & 0.356 \\
\hline Stroke, $n(\%)$ & $46(8.4)$ & $26(3.5)$ & 13.934 & 1 & $<0.001$ \\
\hline Smoking, $\mathrm{n}(\%)$ & $145(26.5)$ & $204(27.8)$ & 0.281 & 1 & 0.596 \\
\hline Drinking, $\mathrm{n}(\%)$ & $74(13.5)$ & $94(12.8)$ & 0.134 & 1 & 0.714 \\
\hline Lack of physical activity, n(\%) & $112(20.4)$ & $113(15.4)$ & 5.514 & 1 & 0.019 \\
\hline Pulse rate, bpm & $76.35(9.11)$ & $74.82(8.40)$ & -3.115 & 1280 & 0.002 \\
\hline Waistline, $\mathrm{cm}$ & $86.77(9.21)$ & $83.26(8.47)$ & -6.979 & 1121.85 & $<0.001$ \\
\hline Hip circumference, $\mathrm{cm}$ & $97.41(6.82)$ & $95.62(6.25)$ & -4.867 & 1280 & $<0.001$ \\
\hline $\mathrm{BMl}, \mathrm{kg} / \mathrm{m}^{2}$ & $25.87(3.37)$ & $24.58(2.95)$ & -7.177 & 1087.29 & $<0.001$ \\
\hline $\mathrm{SBP}, \mathrm{mmHg}$ & $149.26(14.88)$ & $119.39(9.45)$ & -41.205 & 867.62 & $<0.001$ \\
\hline $\mathrm{DBP}, \mathrm{mmHg}$ & $89.80(9.65)$ & $75.87(6.17)$ & -29.572 & 871.13 & $<0.001$ \\
\hline $\mathrm{FBG}, \mathrm{mmol} / \mathrm{L}$ & $5.48(5.15,6.01)$ & $5.32(5.01,5.66)$ & 163,777 & - & $<0.001$ \\
\hline $\mathrm{TG}, \mathrm{mmol} / \mathrm{L}$ & $1.64(1.17,2.22)$ & $1.28(0.97,1.78)$ & 150,027 & - & $<0.001$ \\
\hline $\mathrm{TC}, \mathrm{mmol} / \mathrm{L}$ & $5.14(1.00)$ & $4.96(1.00)$ & -3.177 & 1280 & 0.002 \\
\hline $\mathrm{LDL}-\mathrm{c}, \mathrm{mmol} / \mathrm{L}$ & $3.40(0.88)$ & $3.24(0.88)$ & -3.182 & 1280 & $<0.001$ \\
\hline $\mathrm{HDL}-\mathrm{c}, \mathrm{mmol} / \mathrm{L}$ & $1.39(0.31)$ & $1.43(0.32)$ & 1.893 & 1280 & 0.059 \\
\hline ApoE $\varepsilon 4, n(\%)$ & $70(14.06)$ & $103(15.42)$ & 0.426 & 2 & 0.808 \\
\hline$A \beta_{42}, \mathrm{pg} / \mathrm{mL}$ & $40.64(6.32)$ & $40.94(6.41)$ & 0.842 & 1280 & 0.400 \\
\hline $\mathrm{A} \beta_{40}, \mathrm{pg} / \mathrm{mL}$ & $53.05(8.82)$ & $52.13(8.98)$ & -1.828 & 1280 & 0.068 \\
\hline
\end{tabular}

Unpaired Student's $t$-test and mean \pm SD were used to compare the difference of the approximately normally distributed continuous variables between high blood pressure and normal blood pressure group. Mann-Whitney $\mathrm{U}$ test and mediam (quartile) were used for the skew distributional data and Chi square and percentage were used for categorical variables. Data are mean (SD), median (interquartile range), or number (percentage). BMI, body mass index. SBP, systolic blood pressure. DBP, diastolic blood pressure. FBG, fast blood glucose. A $\beta$, amyloid beta. TC, total cholesterol. TG, triglyceride. HDL-c, high-density lipoprotein. LDL-c, low-density lipoprotein. ApoE, apolipoprotein E

c was the single negative predictor [24]. A double-blind, randomized, placebo-controlled study showed that after giving subjects with lovastatin $40 \mathrm{mg}$ or $60 \mathrm{mg}$ per day for 3 months, serum $A \beta$ concentrations were lower than baseline measurements compared with the placebo group [25]. There was also reports in the literature that pravastatin at $10 \mathrm{mg} / \mathrm{d}$ does not decrease plasma levels of either $A \beta_{40}$ or $A \beta_{42}$ in humans [26]. The possible reason for the difference between the reported results in the literature and our study may be the research population, inclusion criteria, exclusion criteria and method for measuring $A \beta$ has not been unified [27]. Compared with the INNO-BIA assay, the ELISA measured $A \beta_{40}$ levels are slightly lower and $A \beta_{42}$ levels are slightly higher [27]. Our previous research has proved the methods are credible [28, 29]. More research is still needed.

In present study, we did not find the relationship between dyslipidemia and plasma $A \beta$ levels in the total population. However, after stratified by blood pressure, we found that TC and LDL-c were positively correlated with plasma $A \beta_{42}$ levels in normal blood pressure, but not in the hypertension group, indicated that the relationship between blood lipids and $A \beta$ is confounded by the blood pressure. Hypertension is the most important risk factor for cardiovascular disease and stroke. Also, growing evidence indicate that hypertension is a major risk factor for AD. Hypertension has an effect on blood lipids and $A \beta$ [30]. Elevated blood pressure had effects on the $A \beta$ [3133]. Our previous study found that elevation in PP was associated with increased plasma $A \beta_{40}$ and decreased logtransformed soluble advanced glycosylation end productspecific receptor (sRAGE), the underlying mechanism may be relevant to peripheral $A \beta$ clearance [31]. Therefore, we explored the effect of blood pressure on the relationship between blood lipids and plasma $\mathrm{A} \beta$.

The mechanism of dislipidemia related to plasma $A \beta$ levels is not clear. Hypercholesterolemia may cause the deposition of $A \beta$ in the brain by affecting the translocation 


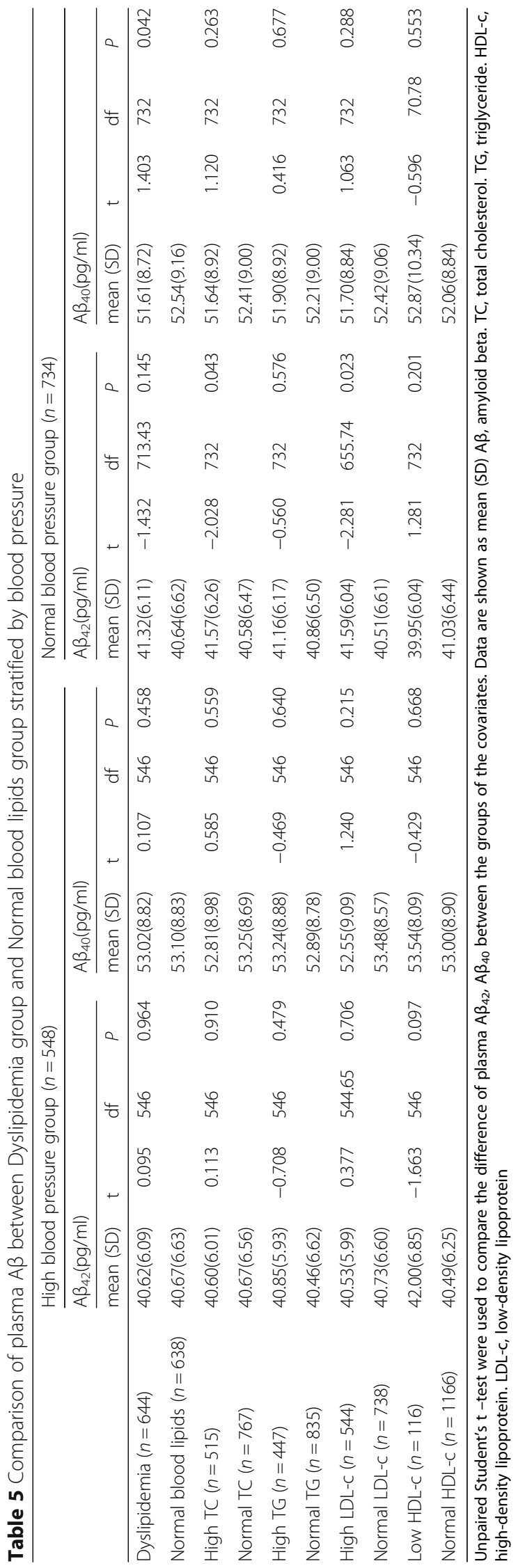



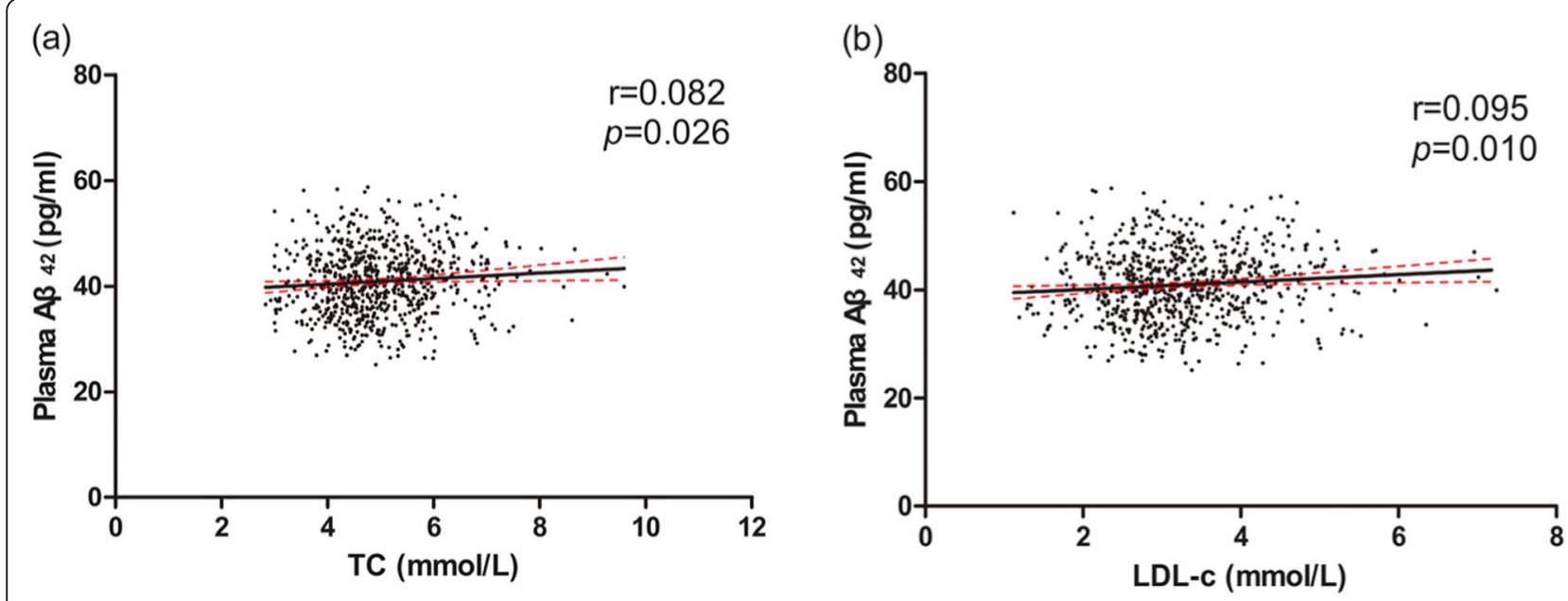

Fig. 4 Correlations of $T C, L D L-C$ and plasma $A \beta_{42}$ in normal blood pressure group. Simple linear correlations between $T C$, $L D L-C$ and plasma $A \beta_{42}$ were shown respectively in picture $(\mathbf{a}, \mathbf{b})$. A $\beta$, amyloid beta. TC, total cholesterol. $L D L-C$, low-density lipoprotein

of endothelial cells across the BBB [34]. The injured BBB in turn induces inflammation, resulting in an increase gap of brain microvascular endothelial cells $[35,36]$. The damage of BBB may affect the expression of low-density lipoprotein receptor-related protein 1 (LRP1) and decrease the function of $A \beta$ transport out of the brain. It may also promotes the expression of RAGE and increase the transport of plasma $A \beta$ to the central nervous system, which ultimately causes $A \beta$ deposition in the brain [37]. These findings suggest that dyslipidemia is associated with increased $A \beta$ deposition in the brain. The process of brain $A \beta$ from the center to the periphery is its main pathway of clearance, elevated plasma $A \beta$ levels associated with increased $A \beta$ deposition in the brain [38]. Therefore, blood lipids are associated with plasma $A \beta$ may relate to the increased deposition of $A \beta$ in the brain.

Recent years, study had also suggested that hyperlipidemia can affect $\mathrm{A} \beta$ metabolism [39]. TC is mainly concentrated in membrane microdomains termed lipid rafts where considerable evidence indicates that the amyloidogenic processing of APP largely occurs [39]. TC can enhance the activity of BACE1 (the rate-limiting enzyme for $A \beta$ generation) and promote it's localization to lipid rafts, otherwise, it can also act as a positive regulator of $\gamma$-secretase to further increase the activity of it [40]. BACE1 transcription increased in mice feed with high-

Table 6 Multiple linear regression models of blood lipids and plasma A levels stratified by blood pressure

\begin{tabular}{|c|c|c|c|c|c|c|c|c|c|c|c|c|}
\hline & \multicolumn{6}{|c|}{ High blood pressure group $(n=548)$} & \multicolumn{6}{|c|}{ Normal blood pressure group $(n=734)$} \\
\hline & \multicolumn{3}{|c|}{$A \beta_{42}(\mathrm{pg} / \mathrm{ml})$} & \multicolumn{3}{|c|}{$A \beta_{40}(\mathrm{pg} / \mathrm{ml})$} & \multicolumn{3}{|c|}{$A \beta_{42}(\mathrm{pg} / \mathrm{ml})$} & \multicolumn{3}{|c|}{$A \beta_{40}(p g / m l)$} \\
\hline & $\beta$ & $\mathrm{t}$ & $P$ & $\beta$ & $\mathrm{t}$ & $P$ & $\beta$ & $\mathrm{t}$ & $P$ & $\beta$ & $\mathrm{t}$ & $P$ \\
\hline \multicolumn{13}{|l|}{ Model 3} \\
\hline TG & 0.661 & 1.849 & 0.065 & 0.618 & 1.220 & 0.223 & -0.532 & -1.609 & 0.108 & -0.224 & -0.480 & 0.631 \\
\hline TC & -0.442 & -1.273 & 0.203 & -0.885 & -1.886 & 0.060 & 0.666 & 2.267 & 0.024 & 0.084 & 0.204 & 0.838 \\
\hline $\mathrm{HDL}-\mathrm{C}$ & -1.525 & -1.392 & 0.165 & 0.503 & 0.324 & 0.746 & 0.100 & 0.102 & 0.919 & -1.566 & -1.130 & 0.259 \\
\hline ApoE $\varepsilon 4$ & 0.305 & 0.372 & 0.710 & -0.727 & -0.627 & 0.531 & 1.207 & 1.755 & 0.080 & 1.083 & 1.117 & 0.264 \\
\hline \multicolumn{13}{|l|}{ Model 4} \\
\hline TG & 0.552 & 1.685 & 0.093 & 0.466 & 1.006 & 0.315 & -0.423 & -1.371 & 0.171 & -0.185 & -0.426 & 0.670 \\
\hline LDL-C & -0.363 & -1.088 & 0.277 & -0.986 & -2.090 & 0.037 & 0.743 & 2.558 & 0.011 & 0.013 & 0.031 & 0.976 \\
\hline $\mathrm{HDL}-\mathrm{C}$ & -1.942 & -1.935 & 0.053 & -0.259 & -0.182 & 0.855 & 0.689 & 0.786 & 0.432 & -1.435 & -1.160 & 0.247 \\
\hline ApoE $\varepsilon 4$ & 0.304 & 0.370 & 0.711 & -0.707 & -0.610 & 0.542 & 1.203 & 1.751 & 0.080 & 1.093 & 1.128 & 0.260 \\
\hline
\end{tabular}

$\beta$, the unstandardized regression coefficient

Model 3: adjust for sex, age, education years, smoking, drinking, lack of physical activity, cardiovascular disease, waistline and lip circumference, pulse rate, SBP, DBP, FBG, TC, TG, HDL-c, BMI and ApoE genotype. BMI, body mass index. SBP, systolic blood pressure. DBP, diastolic blood pressure. FBG, fast blood glucose $A \beta$, amyloid beta. TC, total cholesterol. TG, triglyceride. HDL-c, high-density lipoprotein. LDL-c, low-density lipoprotein. ApoE, apolipoprotein E

Model 4: adjust for sex, age, education years, smoking, drinking, lack of physical activity, cardiovascular disease, waist and lip circumference, pulse rate, SBP, DBP, FGB, LDL-c, TG, HDL-c, BMI and ApoE genotype. BMI, body mass index. SBP, systolic blood pressure. DBP, diastolic blood pressure. FBG, fast blood glucose A 3 , amyloid beta. TC, total cholesterol. TG, triglyceride. HDL-c, high-density lipoprotein. LDL-c, low-density lipoprotein. ApoE, apolipoprotein E 
fat and TC, suggesting that hypercholesterolemia increases the production of $A \beta$ by affecting the activity of secretase [41]. In addition, increased TC in cell membranes can inhibit the function of $\alpha$-secretase, promote the cleavage of APP by $\beta$-secretase and $\gamma$-secretase, and eventually lead to increased $A \beta$ production [42].

An important question is why TC and LDL-c are related to plasma $A \beta_{42}$ in normal blood pressure, and why LDL-c is correlated with plasma $A \beta_{40}$ in high blood pressure rather than $A \beta_{42}$. A $\beta$ peptides are mainly produced in the brain, are transported to the cerebrospinal fluid and plasma, and are degraded in the periphery [43]. This degradation is of importance as it allows lowering the whole brain $A \beta$ content. $A \beta$ peptides, particularly $A \beta_{42}$, are highly water insoluble molecules requiring lipid environments to be transported to the places of their degradation or excretion [44]. In addition, in normal blood pressure, the blood vessels walls are not damaged and transportation of $A \beta$ is unrestricted. This is not the case in high blood pressure, where blood vessels might be damaged and transportation of $A \beta$ peptides is consequently deteriorated. Therefore, in normal blood pressure, $A \beta_{42}$ correlated with TC and LDL-c may as it's strongly hydrophobic and the integrity of the vascular wall. In high blood pressure, $A \beta_{40}$ peptides negatively associated with LDL-c as lower amount of $A \beta$ peptides are transported through the blood vessels at all. Moreover, $\mathrm{A} \beta$ is highly hydrophobic peptides and requires lipid environment for its solubility. Positive correlation of TC and LDL-c with $A \beta_{42}$ might simply reflect the better condition for solubility.

\section{Limitations}

First, the design of this study did not allow for causal assumptions between plasma $A \beta$ levels and dyslipidemia. It was difficult to determine whether dyslipidemia led to plasma $A \beta$ change. The results need to be validated in additional longitudinal cohort studies. Second, we did not analyze the relationships of dyslipidemia and plasma $\mathrm{A} \beta$ levels in mild cognitive impairment (MCI) or dementia patients because of the rather small sample size. Third, $A \beta$ deposition in the brain or CSF could not be obtained. The effects of peripheral $A \beta$ clearance on brain $A \beta$ accumulation must be investigated. Finally, we did not detect blood oxidized low-density lipoprotein (oxLDL) level. It has been reported that ox-LDL is more toxic and plays a more important role in the pathogenesis of AD [45].

\section{Conclusions}

In summary, out research find that elevated plasma $A \beta_{42}$ levels are associated with higher TC and higher LDL-c in normal blood pressure. Elevated plasma $A \beta_{40}$ levels are associated with lower LDL-c in high blood pressure.
This indicated that the relationship between blood lipids and plasma $A \beta$ was confounded by blood pressure. Considering the close relationship between plasma $A \beta$ and deposition in the brain, we explore the relationship between plasma $A \beta$ and blood lipids to provide some help for the auxiliary diagnosis of AD. Additional large-scale cohort studies and convincible evidence-based medical researches are required.

\section{Abbreviations \\ AD: Alzheimer's disease; APP: Amyloid beta protein precursor; AB: Amyloid beta; BBB: Blood brain barrier; DBP: Diastolic blood Pressure; FBG: Fast blood glucose; HDL-c: High-density lipoprotein; LDL-c: Low-density lipoprotein; LRP1: Low-density lipoprotein receptor-related protein 1; PCR: Polymerase chain reaction; PP: Pulse pressure; RAGE: Advanced glycosylation end product-specific receptor; SBP: Systolic blood pressure; TC: Total cholesterol; TG: Triglyceride}

\section{Acknowledgements}

We were thankful for the cooperation of all participants in our study.

\section{Authors' contributions}

HNW took part in the survey, did the statistical analysis and wrote the manuscript. GL performed the analysis and data acquisition. SSH designed the study, collected and took part in the statistical analysis. WS contributed to the treatment of the blood specimens. CC, JY, DL, WJ, HK, DMY, and WJY took part in the survey and collected samples. QQM provided technical guidance in all stages of the study. All authors have read and approved the final article.

\section{Funding}

This work was supported by the Nature Science Foundation of China (No. 81771168) and the Key Research \& Development Programs of Shanxi Province (No. 2018ZDXM-SF-052).

\section{Availability of data and materials}

The data used in this study are available from the corresponding author if needed.

\section{Ethics approval and consent to participate}

All individuals received information about the study and were able to cooperate to complete the questionnaire survey. For illiterate participants, their relatives agreed on the informed consent. The privacy rights of the participants had always been observed. The Ethics Committee of The First Affiliated Hospital of Xi'an JiaoTong University gave ethical approval.

\section{Consent for publication}

All the participants provided written informed consent for the publication of the results of this study.

\section{Competing interests}

The authors declare that they have no competing interests.

\section{Author details}

'Department of Neurology, The First Affiliated Hospital of Xi'an Jiaotong University, 277 West Yanta Rd, Xi'an 710061, China. ${ }^{2}$ Huyi Hospital of Traditional Chinese Medicine, Xi'an, China.

Received: 25 July 2019 Accepted: 10 January 2020

Published online: 14 January 2020

References

1. Hardy J, Selkoe DJ. Medicine - the amyloid hypothesis of Alzheimer's disease: Progress and problems on the road to therapeutics. Sci. 2002;297: 353-6.

2. Chow WW, Mattson MP, Wong PC, Gleichmann M. An overview of APP processing enzymes and products. NeuroMolecular Med. 2010;12:1-12.

3. Blennow $\mathrm{K}$, Hampel $\mathrm{H}$, Weiner M, Zetterberg $\mathrm{H}$. Cerebrospinal fluid and plasma biomarkers in Alzheimer disease. Nat Rev Neurol. 2010;6:131-44. 
4. Querfurth HW, LaFerla FM. Mechanisms of disease Alzheimer's disease. N Engl J Med. 2010;362:329-44.

5. Shah NS, Vidal JS, Masaki K, Petrovitch H, Ross GW, Tilley C, et al. Midlife blood pressure, plasma beta-amyloid, and the risk for Alzheimer disease the Honolulu Asia aging study. Hypertens. 2012;59:780-U782.

6. DeMattos RB, Bales KR, Cummins DJ, Paul SM, Holtzman DM. Brain to plasma amyloid-beta efflux: a measure of brain amyloid burden in a mouse model of Alzheimer's disease. Sci. 2002;295:2264-7.

7. Schilling S, Tzourio C, Soumare A, Kaffashian S, Dartigues JF, Ancelin ML, et al. Differential associations of plasma lipids with incident dementia and dementia subtypes in the $3 \mathrm{C}$ study: a longitudinal, population-based prospective cohort study. PLoS Med. 2017;14.

8. Reitz C, Tang MX, Schupf N, Manly JJ, Mayeux R, Luchsinger JA. Association of Higher Levels of high-density lipoprotein cholesterol in elderly individuals and lower risk of late-onset Alzheimer disease. Arch Neurol. 2010;67:1491-7.

9. Cedazo-Minguez A, Ismail MA, Mateos L. Plasma cholesterol and risk for late-onset Alzheimer's disease. Expert Rev Neurother. 2011;11:495-8.

10. Kivipelto M, Helkala EL, Laakso MP, Hanninen T, Hallikainen M, Alhainen K, et al. Midlife vascular risk factors and Alzheimer's disease in later life: longitudinal, population based study. Br Med J. 2001:322:1447-51.

11. Solomon A, Kareholt I, Ngandu T, Winblad B, Nissinen A, Tuomilehto J, et al. Serum cholesterol changes after midlife and late-life cognition - twentyone-year follow-up study. Neurol. 2007;68:751-6.

12. Sparks DL, Scheff SW, Hunsaker JC, Liu HC, Landers T, Gross DR. Induction of Alzheimer-like Beta-amyloid Immunoreactivity in the brains of rabbits with dietary-cholesterol. Exp Neurol. 1994;126:88-94.

13. Simons M, Keller P, De Strooper B, Beyreuther K, Dotti CG, Simons K Cholesterol depletion inhibits the generation of beta-amyloid in hippocampal neurons. Proc Natl Acad Sci U S A. 1998;95:6460-4.

14. Li G, Shofer JB, Kukull WA, Peskind ER, Tsuang DW, Breitner JCS, et al. Serum cholesterol and risk of Alzheimer disease - a community-based cohort study. Neurol. 2005;65:1045-50.

15. Mielke MM, Zandi PP, Sjogren M, Gustafson D, Ostling S, Steen B, et al. High total cholesterol levels in late life associated with a reduced risk of dementia. Neurol. 2005;64:1689-95.

16. Stewart $R$, White $L R$, Xue QL, Launer $L$. Twenty-six-year change in total cholesterol levels and incident dementia - the Honolulu-Asia aging study. Arch Neurol. 2007;64:103-7.

17. Mancia G, Fagard R, Narkiewicz K, Redon J, Zanchetti A, Bohm M, et al. ESH/ ESC guidelines for themanagement of arterial hypertension the task force for the management ofarterial hypertension of the European society ofHypertension (ESH) and of the European Society of Cardiology (ESC). Hypertens. 2013;2013(31):1281-357.

18. Xu Y, Wang LM, He J, Bi YF, Li M, Wang TG, et al. Prevalence and control of diabetes in Chinese adults. JAMA. 2013;310:948-58.

19. Kanekiyo T, Xu HX, Bu GJ. ApoE and a beta in Alzheimer's disease: accidental encounters or partners? Neuron. 2014;81:740-54

20. Proitsi P, Kim M, Whiley L, Simmons A, Sattlecker M, Velayudhan L, et al. Association of blood lipids with Alzheimer's disease: a comprehensive lipidomics analysis. Alzheimers Dement. 2017;13:140-51.

21. Ancelin ML, Ripoche E, Dupuy AM, Barberger-Gateau P, Auriacombe S, Rouaud $\mathrm{O}$, et al. Sex differences in the associations between lipid levels and incident dementia. J Alzheimers Dis. 2013;34:519-28.

22. Abdullah L, Luis C, Paris D, Ait-ghezala G, Mouzon B, Allen E, et al. High serum a beta and Vascular risk factors in first-degree relatives of Alzheimer's disease patients. Mol Med. 2009;15:95-100.

23. Balakrishnan K, Verdile G, Mehta PD, Beilby J, Nolan D, Galvao DA, et al. Plasma a beta 42 correlates positively with increased body fat in healthy individuals. J Alzheimers Dis. 2005;8:269-82.

24. Blasko I, Kemmler G, Jungwirth S, Wichart I, Weissgram S, Jellinger $\mathrm{K}$, et al. Prospective study on association between plasma amyloid beta-42 and atherosclerotic risk factors. J Neural Transm. 2011;118:663-72.

25. Friedhoff LT, Cullen El, Geoghagen NSM, Buxbaum JD. Treatment with controlled-release lovastatin decreases serum concentrations of human beta-amyloid (a beta) peptide. Int J Neuropsychopharmacol. 2001;4:127-30.

26. Ishii K, Tokuda T, Matsushima T, Miya F, Shoji S, Ikeda S, et al. Pravastatin at $10 \mathrm{mg} /$ day does not decrease plasma levels of either amyloid-beta (a beta) 40 or a beta 42 in humans. Neurosci Lett. 2003;350:161-4.

27. Brown BM, Peiffer JJ, Taddei K, Lui JK, Laws SM, Gupta VB, et al. Physical activity and amyloid-beta plasma and brain levels: results from the
Australian imaging, biomarkers and lifestyle study of ageing. Mol Psychiatry. 2013;18:875-81.

28. Zhao BY, Shang SH, Li P, Chen C, Dang LJ, Jiang Y, et al. The gender- and age- dependent relationships between serum lipids and cognitive impairment: a cross-sectional study in a rural area of Xi'an, China. Lipids Health Dis. 2019:18.

29. Gao L, Jiang Y, Wei S, Shang S, Li P, Chen C, et al. The level of plasma amyloid-beta(40) is correlated with peripheral transport proteins in cognitively Normal adults: a population-based cross-sectional study. J Alzheimers Dis. 2018;65:951-61.

30. Sharma R, Raghuram TC, Rao UB, Moffatt RJ, Krishnaswamy K. The effect of fat intake and antihypertensive drug therapy on serum lipid profile: a crosssectional survey of serum lipids in male and female hypertensives. Mol Cell Biochem. 2010;343:37-47.

31. Jiang Y, Shang SH, Li P, Chen C, Dang L, Wang JJ, et al. Pulse pressure is associated with plasma amyloid-beta transport dysfunction. J Hypertens. 2018;36:569-79.

32. Zhao W, Wang J, Ho L, Ono K, Teplow DB, Pasinetti GM. Identification of antihypertensive drugs which inhibit amyloid-beta protein Oligomerization. J Alzheimers Dis. 2009;16:49-57.

33. Langbaum JBS, Chen KW, Launer LJ, Fleisher AS, Lee W, Liu XF, et al. Blood pressure is associated with higher brain amyloid burden and lower glucose metabolism in healthy late middle-age persons. Neurobiol Aging. 2012;33.

34. Cao DF, Fukuchi Kl, Wan H, Kim H, Li L. Lack of LDL receptor aggravates learning deficits and amyloid deposits in Alzheimer transgenic mice. Neurobiol Aging. 2006;27:1632-43.

35. Ehrlich D, Humpel C. Chronic vascular risk factors (cholesterol, homocysteine, ethanol) impair spatial memory, decline cholinergic neurons and induce blood-brain barrier leakage in rats in vivo. J Neurol Sci. 2012; 322:92-5.

36. Acharya NK, Levin EC, Clifford PM, Han M, Tourtellotte R, Chamberlain D, et al. Diabetes and hypercholesterolemia increase blood-brain barrier permeability and brain amyloid deposition: beneficial effects of the LPPLA2 inhibitor Darapladib. J Alzheimers Dis. 2013;35:179-98.

37. Chen C, Li XH, Tu Y, Sun HT, Liang HQ, Cheng SX, et al. A beta-AGE AGGR AVATES COGNITIVE DEFICIT IN RATS VIA RAGE PATHWAY. Neurosci. 2014; 257:1-10.

38. Marques MA, Kulstad JJ, Savard CE, Green PS, Lee SP, Craft S, et al. Peripheral amyloid-beta levels regulate amyloid-beta clearance from the central nervous system. J Alzheimers Dis. 2009;16:325-9.

39. Gamba P, Testa G, Sottero B, Gargiulo S, Poli G, Leonarduzzi G. The link between altered cholesterol metabolism and Alzheimer's disease. Environ Stressors Biol Med. 2012;1259:54-64.

40. Wahrle S, Das P, Nyborg AC, McLendon C, Shoji M, Kawarabayashi T, et al. Cholesterol-dependent gamma-secretase activity in buoyant cholesterol-rich membrane microdomains. Neurobiol Dis. 2002;9:11-23.

41. Wang RS, Li JJ, Diao SY, Kwak YD, Liu L, Zhi LT, et al. Metabolic stress modulates Alzheimer's beta-Secretase gene transcription via SIRT1-PPAR gamma-PGC-1 in neurons. Cell Metab. 2013;17:685-94.

42. Vetrivel KS, Thinakaran G. Membrane rafts in Alzheimer's disease betaamyloid production. Biochim Biophys Acta. 1801;2010:860-7.

43. Tarasoff-Conway JM, Carare RO, Osorio RS, Glodzik L, Butler T, Fieremans E, et al. Clearance systems in the brain-implications for Alzheimer disease. Nat Rev Neurol. 2015;11:457-70.

44. Jung SS, Nalbantoglu J, Cashman NR. Alzheimer's beta-amyloid precursor protein is expressed on the surface of immediately ex vivo brain cells: a flow cytometric study. J Neurosci Res. 1996;46:336-48.

45. Aldred S, Bennett S, Mecocci P. Increased low-density lipoprotein oxidation, but not total plasma protein oxidation, in Alzheimer's disease. Clin Biochem. 2010;43:267-71.

\section{Publisher's Note}

Springer Nature remains neutral with regard to jurisdictional claims in published maps and institutional affiliations. 